\title{
Literature Growth and Development of "E-learning": A Bibliometric Analysis using Bibexcel
}

\author{
Thirumagal A, Mani M \\ Manonmaniam Sundaranar University \\ Tirunelveli \\ India \\ athirumagala@yahoo.co.in
}

ABSTRACT: E-Learning is supported by Information Communication Technology. It is very important to Library professionals. The data was downloaded from Web of Knowledge from 2010 to 2014 for five years. The data was downloaded as plain text format. Each and every analysis was done with Bibexcel and Pajek tool. This article is particularly focus on highly productive author's h-index, co-authorship pattern of cluster analysis, countries collaboration, and google map.

Keywords: E-learning, Authorship Pattern, Collaboration, Bibliometric Analysis, Bibexcel, Pajek, and Gpsvisualizer

Received: 1 March 2019, Revised 12 April 2019, Accepted 19 May 2019

DOI: $10.6025 / \mathrm{jism} / 2019 / 9 / 3 / 108-114$

(C) 2019 DLINE. All Rights Reserved

\section{Introduction}

E-learning brings the world to a student's fingertips and lets the student move freely about the globe. It is the greatest tool now available to uplift the exploited and marginalized section of our society. The data was downloaded from Web of Knowledge for five years. The Web of Knowledge database is covered with Science Citation Index (SCI), Social Science Citation Index (SSCI), Arts and Humanities Citation Index (A\&HCI). In the Web of Knowledge Database the key word "E-Learning" was used in the Topic field for the 2010 to 2014. The result of 2262 was downloaded in a separate text files. The data were analysis with the Bibexcel. It is a dominant analytical tool. This Bibexcel was developed by Olle Persson. This software is very useful for bibliometric analysis of the data.

\section{Limitations}

This research is concentrated on "E-learning" publications. The records are collected from Web of Science database for the period of 2010 - 2014. Total number of publications collected for this study was 2262 . The data was downloaded in plain text format.

\section{Data Analysis}

"Bibexcel" a popular toolbox was used to analyze the data. Bibexcel was developed by Olle Persson, inforsk, Umea univ (Sweden). This software is intended to assist a user in analyzing bibliometric data or any data of a textual nature formatted in a similar manner.

\begin{tabular}{llllll}
\hline 108 & Journal of Information \& Systems Management Volume 9 & Number 3 & September 2019 \\
\hline
\end{tabular}




\section{Objectives of the Study}

- To examine the Publication Type and year

- Find the Authorship Pattern

- Assure the h-index of highly productive authors and find out cluster Analysis.

- Find out Country and Countries Collaboration

\section{Publication Type of E-Learning}

There is some ups and downs in the research of E-Learning. But there is a gradual growth in publications. The highest publication in the year 2012 with $479(21.18 \%)$ results. The year-wise distribution of literature shows in the below Table - 1 . Scientific research normally published in the article. For this e-learning research 1925 (85.1\%) of works published as Article. The research published in fifteen languages. Out of this, in English language 2135 (94.38\%) published. Because it is the communicative language to most of the scientific people.

\begin{tabular}{|c|c|c|c|}
\hline S.No & Year & No.of Records & $\%$ \\
\hline 1 & 2010 & 401 & 17.72 \\
\hline 2 & 2011 & 471 & 20.82 \\
\hline 3 & 2012 & 479 & 21.18 \\
\hline 4 & 2013 & 451 & 19.94 \\
\hline 5 & 2014 & 460 & 20.34 \\
\hline Total & & 2262 & 100 \\
\hline
\end{tabular}

Table 1. Distribution of literature in E-Learning

The authorship pattern is presented in Table -2 . The table shows that nearly $16.84 \%$ of the contributors were only by single authors, $22.9 \%$ is two authors and three authors by $24 \%$ research output. Twenty eight authors jointly produce one research. For fifteen works there is no authors.

\section{Find highly Productive Author's H-index}

The Scientific value of an author is measured with h-index. H-index is named after Hirsch. He confirmed with a simple procedure, arrange all the cited articles according to decreasing numbers of reference of each article, most cited article on the top, the sequence of serial number is higher than the number of citations. This is h-index. We can find out authors h-index with the help of Bibexcel tool. 6480 authors produce 2262 research work from 2010 to 2014 . With the author field "AU" we got the .doc file, we are adding new field with "tc" to get number of times cited result .jn1 file. Select .jn1 file, type 2/3 "The Box" run Edit outfiles/Select columns. The result is .col file then, run Analyze/h-index. The outcome is .hdx file. We can open in excel format. The answer is like this below table - 3. Wang MH author publish 10 research output. His h-index is 7 . His 7 article received 112 citation. But his total citation for his publication is 117 . But Loia V published 6, his h-index is also 5. This table shows the top 15 scientist's h-index, name citation total sum for h-index, all citations and the author's total number of articles for e-learning research. 


\begin{tabular}{|l|l|l|l|}
\hline S.No & Authorship & Records & $\mathbf{\%}$ \\
\hline 1. & Single & 381 & 16.84 \\
\hline 2. & Two & 518 & 22.9 \\
\hline 3. & Three & 543 & 24 \\
\hline 4. & Four & 318 & 14.06 \\
\hline 5. & Five & 196 & 8.67 \\
\hline 6 & .Six & 113 & 5 \\
\hline 7. & Seven & 57 & 2.52 \\
\hline 8. & Eight & 40 & 1.77 \\
\hline 9. & Nine & 36 & 1.59 \\
\hline 10. & Ten & 17 & 0.75 \\
\hline 11. & More than 10 authors & 43 & 1.9 \\
\cline { 2 - 4 } & Total & 2262 & 100 \\
\hline
\end{tabular}

Table 2. Authorship pattern in e-Learning

\begin{tabular}{|l|l|l|l|l|l|}
\hline S.No & h-index & Author & $\begin{array}{c}\text { Citation sum } \\
\text { within h-core }\end{array}$ & All citations & All articles \\
\hline 1. & 7 & Wang MH & 112 & 117 & 10 \\
\hline 2. & 5 & Loia V & 70 & 73 & 6 \\
\hline 3. & 5 & Gaeta M & 62 & 70 & 9 \\
\hline 4. & 4 & Yang SJH & 77 & 78 & 5 \\
\hline 5. & 4 & Oton S & 33 & 33 & 5 \\
\hline 6. & 4 & Budimac Z & 66 & 70 & 5 \\
\hline 7. & 4 & Klasnja-Milicevic A & 66 & 70 & 5 \\
\hline 8. & 4 & Virvou M & 33 & 33 & 6 \\
\hline 9. & 4 & Barchino R & 33 & 33 & 5 \\
\hline 10. & 4 & Acampora G & 63 & 63 & 4 \\
\hline 11. & 4 & Kinshuk & 77 & 80 & 6 \\
\hline 12. & 4 & Chen NS & 43 & 51 & 7 \\
\hline 13. & 4 & Zhang X & 45 & 45 & 4 \\
\hline 14. & 4 & Vesin B & 66 & 70 & 5 \\
\hline 15. & 4 & Ivanovic M & 66 & 73 & 6 \\
\hline & & & & & \\
\hline
\end{tabular}

Table 3. H-index score for Highly Productive authors 


\section{Cluster Analysis of highly productive authors}

Collaborative research work is good and comfortable. The same scientific groups doing research with themselves. The maximum number of articles produced by a minimum number of authors. For getting the cluster analysis of the author $\mathrm{C} 1$ field was selected. On the basis of the cit file vec file was called created. From Pajek, net file and vec file was called and made cluster map. de-Marcos L[7] done three research with Hilera JR[6]. Martinez JJ[5] all his publications with Hilera JR[6]. The below image shows the number of publications by the individual scientist and the number of collaboration by the individual scientist and the number of collaboration with the other scientific group.

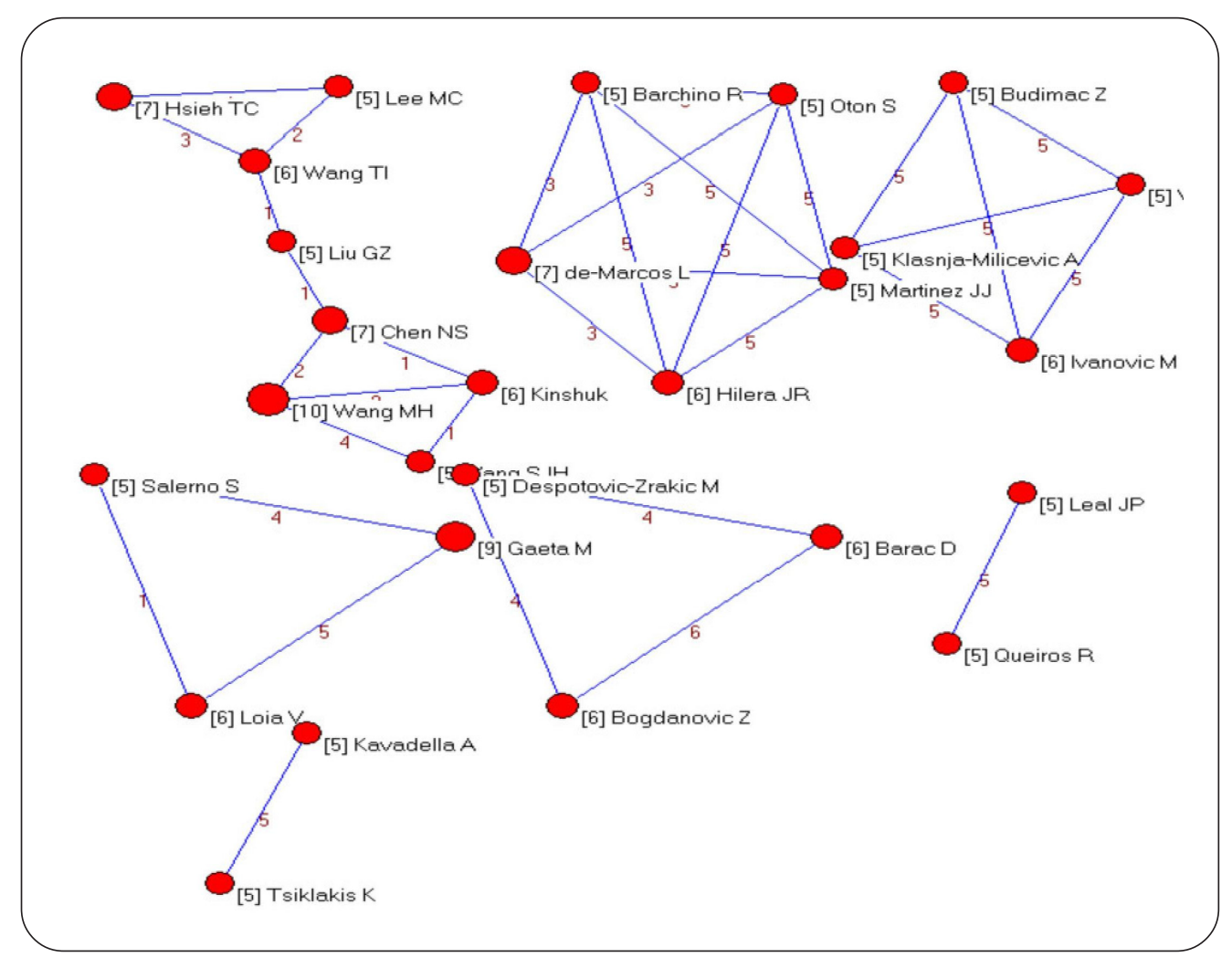

Figure 1. Cluster Analysis of highly productive authors

Country's Contribution in E-Learning: Totally 94 countries contribute research on E-Learning from 2010 to 2014 . We can find Authors address in the $\mathrm{C} 1$ field. On the basis of the $\mathrm{C} 1$ in the Old Tag, we made .out file with whole field intact. With the help of run Edit outfile/remove [..] from whole field, there is no brackets in .wcm file. Then run Edit outfile/Decompress outfile. We got .nnu file, .odr file, .oux file and .cit file. This below table shows that USA with 301 records got First Rank. UK publishes 297 records in the Second Rank and India with 35 output got Twentieth rank.

\section{Country's Collaboration}

Every country is prepared to do collaborative effort with other country. For find countries collaboration, the researcher select the top 32 countries contributing 20 and above research. On the basis of .oux file .net file was created. With the source of cit file vec file was made in Bibexcel. The .net file and vec are called from the Pajek. Here we can find out the number of contributions, name of the country and number of collaborations.

The scientist are willing to share their experience with other country scientists. By their wider study countries teamwork is achievable. The bulk of the ball shows the collaborations. If the number of results are more the size of the ball is very big. India done collaborations with (9)USA, (4)UK, (3)Switzerland, (2) South Africa,(2) Brazil, (2) Germany, one with Australia, Canada, Malaysia, Spain, Taiwan, Ireland, Italy, Japan, Belgium. We can change the color and Arch also. It is very clear. 


\begin{tabular}{|c|c|c|}
\hline S.No & Country & No. of Records \\
\hline 1. & USA & 301 \\
\hline 2. & $\mathrm{UK}$ & 297 \\
\hline 3. & Spain & 258 \\
\hline 4. & Taiwan & 240 \\
\hline 5. & Germany & 124 \\
\hline 6. & Canada & 122 \\
\hline 7. & Australia & 119 \\
\hline 8. & Peoples R China & 92 \\
\hline 9. & Netherlands & 77 \\
\hline 10. & South Korea & 68 \\
\hline 11. & Italy & 61 \\
\hline 12. & Serbia & 57 \\
\hline 13. & Greece & 53 \\
\hline 14. & Turkey & 51 \\
\hline 15. & Switzerland & 46 \\
\hline 16. & Ireland & 41 \\
\hline 17. & France & 40 \\
\hline 18. & Malaysia & 40 \\
\hline 19. & Japan & 40 \\
\hline 20. & India & 35 \\
\hline
\end{tabular}

Table 4. Top 20 Countries contribution in E-Learning

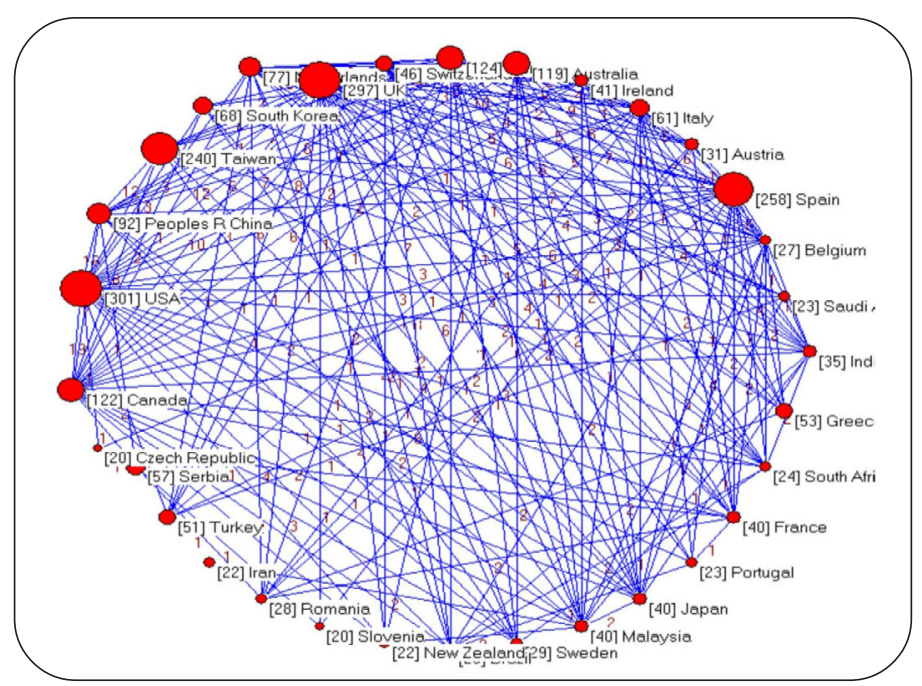

Figure 2. Vector map of Countries and number of collaborations

\begin{tabular}{lllll}
\hline $12 \quad$ Journal of Information \& Systems Management Volume & 9 & Number 3 & September & 2019 \\
\hline
\end{tabular}




\begin{tabular}{|c|c|c|c|}
\hline S.No & Country & Collaborative Country & No. of Records \\
\hline 1. & Canada & USA & 19 \\
\hline 2. & Peoples R China & USA & 16 \\
\hline 3. & Taiwan & USA & 14 \\
\hline 4. & South Korea & USA & 13 \\
\hline 5. & Netherlands & UK & 13 \\
\hline 6. & Switzerland & UK & 13 \\
\hline 7. & Peoples R China & Taiwan & 12 \\
\hline 8. & Germany & UK & 12 \\
\hline 9. & UK & USA & 12 \\
\hline 10. & Australia & UK & 10 \\
\hline 11. & Canada & UK & 10 \\
\hline 12. & Ireland & UK & 10 \\
\hline 13. & Italy & UK & 10 \\
\hline 14. & Austria & Germany & 9 \\
\hline 15. & Australia & USA & 8 \\
\hline 16. & Germany & Switzerland & 8 \\
\hline 17. & Germany & Netherlands & 8 \\
\hline 18. & Germany & Italy & 8 \\
\hline 19. & Peoples R China & UK & 8 \\
\hline 20. & Canada & Taiwan & 8 \\
\hline
\end{tabular}

Table 5. Countries Collaboration in E-Learning

Here 308 countries are done joint work. People R China worked with USA with 69 times. Japan done 34 collaborative work with people R China . India done research with countries like USA (301) UK(9) Japan (6) Malaysia (6) Denmark (5) Italy (5) France (4) Germany (4) South Korea (4) Peoples R China (4) Turkey (4) and so on. It is appreciating situation. Here we can view the top 25 countries collaboration and number of records. With the help of GPS visualizer, we can view the city name and results box, with the specific indication in red drop mark.

\section{Conclusion}

The downloaded data was analysed with Bibexcel tool. Single authors contribution is $16.84 \%$. Most of the research work done by collaborative authors. There is a gradual growth in the publication of e-learning. Most of the scientist are ready to publish their research work in article as $85.1 \%$. Wang MH published 10 research work. His h-index articles citations and total citations of his work. The scientist are ready to do collaborative of his work. The scientist are ready ti do collaborative research with other countries also. 94 countries contributing 2262 results of E-learning. Our country india contributing 35 results. with gps visualizer geocoder we can visualize the city and country name un the global map with red dot mark. Scientific collaboration is accepted in the new interdisciplinary research. By that there is a chance of improving funds and professionel advertisement. 


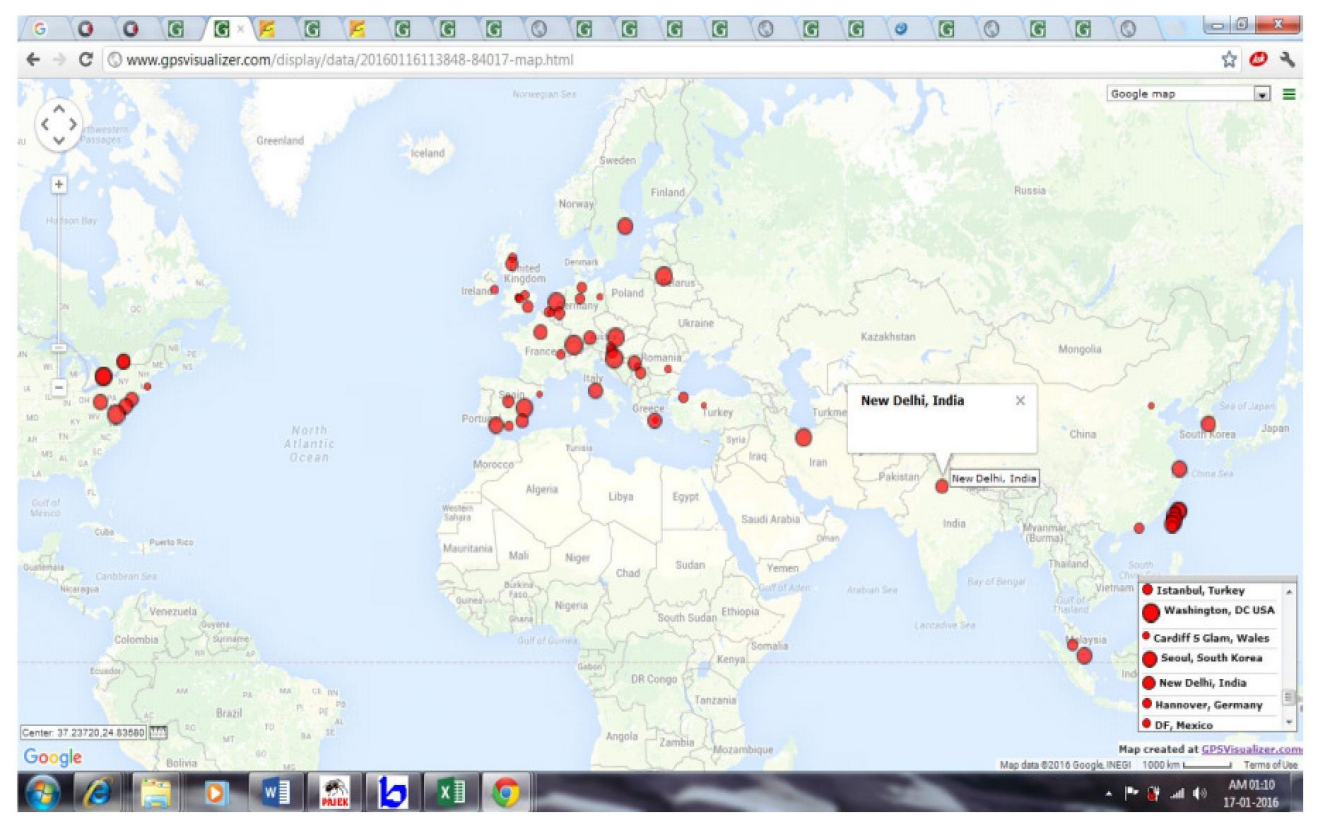

Figure 3. GPS Visualizer Map of E-Learning

\section{References}

[1] Ahmed, K., Gupta, B. (2013). India's Contribution on Antioxidants: A Bibliometric Analysis, 2001-2010. Scientometrics, 94 (2) 741-754.

[2] Aswathy, S., Gopikuttan, A. (2012). Journal of Spacecraft and Rockets: A Scientometric Analysis. SRELS Journal of Information Management, 49 (6).

[3] Baskaran, C \& Sivakami, N. (2014). Swine Influenza research output: A Bibliometric Analysis. SRELS Journal of Information Management. 51 (1) 13-20.

[4] Holger Cramer; Romy Lauche. \& Gustav Dobos. (2014) Characteristics of randomized controlled trials of yoga: a bibliometric analysis. BMC Complementary and Alternative Medicine. 14:328.

[5] Kim, M. (2014). A Bibliometric Analysis of Publications by the School of Biological Sciences, Seoul National University, South Korea. Scientometrics, 98 (2) 999-1019.

[6] Malathy, S., \& Kantha, P. (2015). Journal of Spacecraft Technology: A Bibliometric Study. SRELS Journal of Information Management, 52 (2) 141-151.

[7] Rabindra K; Maharana.\& Ashok Kumar Das (2014). Growth and Development of LIS Research in India during 1999-2013: A Bibliometric Analysis. Chinese Librarianship, 37 June, 1.

[8] Jennifer Noe \& Julia Furay. (2013). Like a Hurricane: A Citation Analysis of Emergency Management Scholarly Literature. Community and Junior College Libraries, 19 (1-2) 21-50.

[9] http://digital.library.unt.edu/ark:/67531/metadc68034/. Accessed November 15, 2015.

[10] http://www.digit.in/ I am so much thankful to the Olle Persson for his wonderful Bibexcel Tool.

\begin{tabular}{llllll}
\hline 14 & Journal of Information \& Systems Management & Volume 9 & Number 3 & September 2019 \\
\hline
\end{tabular}

